\section{BMJ Open}

Ophthalmology

\title{
Visual impairment and social isolation, depression and life satisfaction among older adults in Ghana: analysis of the WHO's Study on global AGEing and adult health (SAGE) Wave 2
}

John Tetteh (10 ,' Gladys Fordjour, ${ }^{2}$ George Ekem-Ferguson,, ${ }^{3,4}$

Anita Ohenewa Yawson, ${ }^{5}$ Vincent Boima, ${ }^{6}$ Kow Entsuah-Mensah, ${ }^{4}$ Richard Biritwum, ${ }^{1}$ Akye Essuman, ${ }^{1}$ George Mensah, ${ }^{1}$ Alfred Edwin Yawson ${ }^{1}$

To cite: Tetteh J, Fordjour G, Ekem-Ferguson G, et al. Visual impairment and social isolation, depression and life satisfaction among older adults in Ghana: analysis of the WHO's Study on global AGEing and adult health (SAGE) Wave 2. BMJ Open Ophthalmology 2020;5:e000492. doi:10.1136/ bmjophth-2020-000492

- Additional material is published online only. To view please visit the journal online (http://dx.doi.org/10.1136/ bmjophth-2020-000492).

Received 15 April 2020 Revised 28 May 2020 Accepted 30 May 2020

\section{Check for updates}

\section{(C) Author(s) (or their} employer(s)) 2020. Re-use permitted under CC BY-NC. No commercial re-use. See rights and permissions. Published by BMJ.

For numbered affiliations see end of article.

Correspondence to Dr Alfred Edwin Yawson; aeyawson@ug.edu.gh

\section{ABSTRACT}

Aim To estimate the prevalence of visual impairment (VI) and associated factors and further quantify its association with social isolation, depression and life satisfaction among older adults in Ghana.

Methods WHO Study on Global AGEing and Adult Health Ghana dataset for older adults 50 years and above was used for this study. Social isolation, depression and life satisfaction were our primary outcomes with VI being our secondary outcome. We employed negative binomial, Poisson and generalised negative binomial regression models individually modified with Coarsened Exact Matching method of analysis. All analysis was performed by adopting robust SE estimation using Stata V.15.

Results The prevalence of VI was $17.1 \%$ (95\% Cl14.3 to 20.2) and the factors associated include age groups, educational level, religion, region, where the participant was born, and difficulty in work/households activity $(p<0.05)$. The inferential analysis shows that the significant log-likelihood score of social isolation and life satisfaction for older adults with VI was 0.25 more $(95 \% \mathrm{Cl} 0.03$ to 0.47 ) and 0.04 less $(95 \% \mathrm{Cl}-0.08$ to -0.01$)$, respectively, compared with those without VI. The prevalence of depression among older adults with VI was significantly $90 \%$ higher compared with non-VI (adjusted prevalence ratio $(95 \% \mathrm{Cl})=1.90(1.17$ to 3.09$), \mathrm{p}<0.001)$.

Conclusion The prevalence of $\mathrm{VI}$ is associated with increasing age, educational level and self-rated health. VI was identified to be associated with social isolation, depression and diminishing life satisfaction. In order to achieve sustainable development goal \#3, a national focus on geriatric care as part of the implementation of the National Ageing Policy will garner improvement in the quality of life of older adults with visual VI in Ghana. Eye health practitioners at all levels of the health systems should consider the psychosocial consequences of VI for the optimum care of the older adult client.

\section{INTRODUCTION}

The incidence of visual impairment (VI) is on the increase and has become a major public health concern. Globally, it is estimated that

\section{Key message}

What is already known about this subject?

$>$ In lower and middle- income countries, increasing age significantly affect visual impairment in settings where the health system is not very responsive to the needs of the older adult.

What are the new findings?

- This analysis indicates that visual impairment among older adults is associated with social isolation, depression and life satisfaction, in Ghana, a lower middle income setting.

It estimates prevalence and factors associated with visual impairment and quantified the association with social isolation, depression, and life satisfaction in older adults in a setting with a dearth of research on older adults as in other low-income and- middleincome countries; to influence national health and social policy.

How might these results change the focus of research or clinical practice?

These findings will contribute to research in a lowresource setting and highlight the need for comprehensive assessment of older adults with low vision by clinicians.

over 2 billion people are visually impaired, of whom over 1 billion aged 50 years and above being visually impaired from uncorrected refractive errors with major causes including: uncorrected refractive errors, cataract, agerelated macular degeneration, glaucoma, diabetic retinopathy, corneal opacity and trachoma. ${ }^{1}$ In sub-Saharan Africa (SSA), there have been similar reports. The prevalence of VI and blindness in Ghana (urban community) were $17.1 \%$ and $1.2 \%$, respectively. ${ }^{2}$ Increasing age is a significant factor accounting for the high prevalence of VI 
and is projected to increase over time as the older adult population is expected to double by $2050 .{ }^{3}$ A pragmatic approach in addressing the health challenge and in particular eye care needs of this population is imperative.

Many factors have been attributed to be associated with VI some of which includes: with increasing age, ${ }^{14-6}$ education, ${ }^{7}$ sex differential, ${ }^{689}$ chronic health conditions, ${ }^{71011}$ employment and status, ${ }^{6}$ place of residence ${ }^{7}$ and among others. The relationship between VI and health and wellbeing among older adults is numerous and is associated with social isolation, depression and life satisfaction and particularly with mood level and social relationships. ${ }^{12} 13$

Persons with VI have a higher prevalence of depression which is attributed to difficulties with daily functioning. ${ }^{14}$ Evidence exists to indicate that correction for refractive error improves depressive symptoms as well as the healthrelated quality of life of persons with VI. ${ }^{15}$ In addition, persons with VI show a significant reduction in different aspects of quality of life domains (including life satisfaction) and that quality of life is related to the degree of visual impairment, such that blind patients report poor life satisfaction. ${ }^{16}$ Moreover, Zheng et al established that, in a population-based study, VI is associated with declining mental health conditions using both cross-sectional and longitudinal data over time with the strongest association among worsening vision. ${ }^{13} 17$

The association of VI with social isolation, depression and life satisfaction has not been widely studied and very little is known among people with VI in sub-Saharan Africa. This study was conducted to estimate the prevalence of VI and associated factors and further quantify its association with social isolation, depression and life satisfaction among older adults in Ghana using data from the WHO wave 2.

\section{METHODS}

This research involved the WHO Study on Global Ageing and Adult Health (SAGE) wave 2 for Ghana, conducted between 2014 and 2015. WHO SAGE was implemented in six lower to middle income countries including China, Ghana, India, Mexico, Russian Federation and South Africa. SAGE covers a wide range of health indicators including demographic characteristics, visual difficulties, subjective well-being, health state and among others.

\section{STUDY DESIGN}

SAGE Wave 2 adopted a cross-sectional study design with a multistage cluster sampling technique. Details about the study design and procedures for data collection have been published elsewhere. ${ }^{18-20}$

\section{STUDY PARTICIPANTS}

SAGE is a longitudinal study with a nationally representative sample of adults aged 50 years and older, and a smaller comparative sample of persons aged 18-49 years. SAGE primary sampling units (PSUs) were stratified by region and location (urban/rural). The selection of the PSUs was based on proportional allocation by size and random systematic sampling method. Wave 1 respondents were recruited from selected probability sampled EAs using a multistage cluster sampling strategy. EA was selected independently within each stratum with the number of EAs per region based on the population size of the region. ${ }^{18}$

\section{SAGE Wave 2 participants selection}

SAGE Wave 1 involved more than $50 \%$ of participants aged $60+y e a r s$, in contra to that, due to urbanisation and inevitable events (death), SAGE Wave 2 sampling strategy was designed to account for expected attrition. ${ }^{19}$ All wave 1 households $(\mathrm{HH})$ were visited for wave 2 data collection and replacements for sample attrition used a systematic sampling approach to randomly select new households using EA aerial photographic maps on which dwellings are clearly visible, starting at a random point on the periphery of the EA. Mutually exclusive $\mathrm{HH}$ was then classified into: SAGE Wave 1 follow-up households with one or more members aged 50 years or older targeted for selection, new households with one or more members aged 50 years or older, SAGE Wave 1 follow-up households which include residents aged 18-49 targeted for selection, new households which include residents aged $18-49 .^{19}$

A total sample of 4735 respondents was involved for Ghana SAGE Wave 2; however, based on the aim of the study, those below the age of 50 years, missing or not applicable responses, and those designated as do not know responses were excluded. A total sample size of 3575 (comprising 348 newly participants and 3227 follow-ups from wave 1 ) of adults aged 50 years and above was used for this analysis. The choice of study participants was based on the report by WHO that majority of people with vision impairment are over the age of 50 years. ${ }^{1}$

\section{VARIABLE DEFINITION}

Three variables were generated and used in this study, involving non-communicable disease (NCD) status, waist-hip ratio (WHR) and hypertension status (blood pressure (BP)). SAGE Wave 2 asked questions like 'Has a health care professional/doctor ever told you that you have...? Or Have you ever been diagnosed with...?' on these NCDs: angina, arthritis, asthma, cataract, depression, diabetes, hypertension, chronic lung disease and stroke. NCDs status was measured by scoring 1 for 'yes' response and otherwise ' 0 ' for all the nine self-reported chronic health conditions. However, the scores for this study ranges from 0 to 6 which was categorised into 0 'None' and 1 or more as ' $1+\mathrm{NCD}$ '.

WHR was measured and categorised using low if WHR $\leq 0.90$ for males and $\leq 0.85$ for females, moderate if $0.91-0.99$ for males and $0.86-0.89$ for females and high if WHR is $\geq 1.00$ for males and $\geq 0.90$ females based on WHO categorisation. ${ }^{21}$ Meanwhile, mean systolic and diastolic BP for the last two measurements was estimated and further categorised into normal, elevated and hypertension, respectively, if systolic and diastolic 
measures; <120/80 mm Hg, 120-129/80-89 mm Hg and $\geq 130 / 90 \mathrm{~mm} \mathrm{Hg} .{ }^{22}$ The main idea for this categorisation is to assess hypertension status with $\geq 130 / 90 \mathrm{~mm} \mathrm{Hg}$ association with VI compared with normal BP.

\section{DEPENDENT VARIABLE}

The outcomes of interest this research considered as the study domains were social isolation, depression and life satisfaction among participants with VI. The detailed sequence of the domain questions can be found in online supplementary table 1 .

\section{Social isolation}

Social isolation was assessed in SAGE wave 2 on how the participant felt about different aspects of life by reporting how often they felt for three standard questions. These were captured using a Likert scale involving: never, rarely, sometimes and often with scoring $0,1,2$ and 3, respectively. Composite variable was generated with a score ranging from 0 to 9 (mean $(\mathrm{SD})=0.69(1.47)$ ).

\section{Depressive episode}

Depression score was generated from a series of questions based on World Mental Health Survey version of the Composite International Diagnostic Interview ${ }^{23}$ if the participant answered 'yes' in one of the following: if participant during the last 12 months (1) had a period lasting several days when feeling sad, empty or depressed; (2) had a period lasting several days when lost interest in most things usually enjoyed such as personal relationships, work or hobbies/recreation; (3) had a period lasting several days when feeling energy decreased or tired all the time. If anyone of these is 'yes', SAGE Wave 2 further used 15 standard questions to assess depression among those participants. Diagnostic procedure for depressive disorder over the past 12 months was clearly defined by using the WHO ICD-10 classification of mental and behavioural disorders for a major depressive episode (F32). ${ }^{24}$ The algorithm as proposed by Arokiasamy et al was adopted to define depression in our study. First, two categories of independent variables were generated from the index score of depression, categories 1 and 2 individually. Category 1 contained three domains namely: depressive distress, with a minimum duration of 2 weeks and symptoms are present nearly every day, most of the day; tiredness or loss of energy and loss of interest or pleasure in activities, including decreased sexual activity. Category 2 contained 7 domains with 12 items of depressive symptoms secondary to depressive distress: negative thought (frequently feel hopeless, low self-esteem or lost confidence); cognitive difficulties (difficulties in concentration or slowdown in thinking); feel anxious and worried most days; physical difficulty (slowing down in moving around or could not sit); sleep difficulty (problems falling asleep or problems waking up too early); loss of appetite; and suicidal ideas or attempts (tried to end life or wish dead). Each item was coded as 1 'Yes' and 0 'No' and for each category, depressive disorder over the 12 months was considered if score was 2-plus and 4-plus, respectively, for categories 1 and $2 .{ }^{25}$ This method of diagnosing depressive episodes was also adopted by Fernández-Niño et al. ${ }^{26}$

\section{Life satisfaction}

Life satisfaction was also captured in SAGE Wave 2 to examine how satisfied participants were in their lives. Six Likert scale questions were captured with the caption 'How satisfied are you with...' your health; yourself; your ability to perform your daily living activities; your personal relationships; the conditions of your living place; and overall, how satisfied are you with your life as a whole these days? The Likert scale has responses 'very dissatisfied; dissatisfied; neither satisfied nor dissatisfied; satisfied and very satisfied' with recoded scores $0,1,2,3$ and 4 respectively. An index variable with an overall score ranging from 0 to 24 was generated (mean $(\mathrm{SD})=19.56$ $(3.40))$.

For the purpose of reliability and internal consistency, the Jann Stata module was used to compute Cronbach's alpha for weighted data due to SAGE study design on all three domains. ${ }^{27}$ The overall test of reliability for social isolation, depression and life satisfaction was very high and of good quality ( $\alpha=0.93,0.95$ and 0.86 , respectively).

For the secondary outcome variable (visual impairment), SAGE Wave 2 tested distance and near vision among participants with a logMAR chart and was coded as normal, low and impaired.

\section{VISION TEST}

Respondents were invited to sit in a chair positioned so that the respondent's head will be $4 \mathrm{~m}$ from the eye chart (Tumbling 'E' logMAR chart). The interviewer makes sure the participant does not lean in closer to the chart during the test. To measure acuity in the left eye, the right eye was covered with right palm or an eye patch and the subject is asked to respond to each ' $\mathrm{E}$ ' in a row slowly, row by row, with guidance. Only one reading of a given ' $\mathrm{E}$ ' is allowed. The right eye can then be tested in the same way.

\section{Distance vision interviewer}

Distance vision was measured using $4 \mathrm{~m}$ out for a timed walk. If the respondent makes more than two errors in one row and reads all letters in the row, their result is read as the previous row.

\section{Near vision interviewer}

Respondent place the end of the cord attached to the near vision chart between forefinger and middle finger. Then, place the palm over the eye with the same hand. The freehand is used to hold the chart. Responses were verbal (up, down, left and right). If the respondent makes more than two errors in one row and reads all letters in the row, their result is read as the previous row.

For the purpose of our study objective, and impaired vision both for distance and near was categorised as VI, as per the WHO ICD-10 (H54) ${ }^{28}$ Visual acuity was 
classified based on the logMAR chart as normal $(6 / 12)$, low $(6 / 18)$, and impaired $(3 / 60)$ and recategorised into normal or low vision (coded as 0 ) and impaired (coded as 1). The instruments used to measure our outcome variables were pretested and validated before using by SAGE Wave 2 team in Ghana.

\section{INDEPENDENT VARIABLES}

Covariates that were analysed in this study included: sex (male or female), age group (50-59, 60-69, 70-79 and $80+$ ), educational level (none, primary, Senior High School/Middle School Leaving Certificate and tertiary), marital status (never married, separated/ divorced, widowed), religion (none, Christian, Islam and primal indigenous), place of residence (rural vs urban), currently working (no or yes), region (involving the then 10 administrative regions), self-rated health (SRH; good, moderate and bad), a place where born (same locality or different locality), difficulty in work activity (none, mild, moderate, severe, extreme), NCD status (none and $1+\mathrm{NCD})$ and WHR (low, moderate and high) and hypertension status (normal, elevated and hypertensive).

The rationale for the choice of these independent variables was based on previous literature as factors associated with VI locally ${ }^{711}$ and internationally. ${ }^{410} 1729$

\section{DATA ANALYSIS}

To reduce bias in this complex survey data, three approaches to data analysis were carried out, bivariate descriptive statistics with a Rao-Scott $\chi^{2}$ test of an independent association of covariate with VI. Factors influencing VI were estimated by adopting three statistical models that were performed individually involving Poison, Logistic and Probit models. These models were adopted based on the assumption made by Chen et al that occasionally, the OR estimated from logistic regression approximates the prevalence ratio from Poisson estimates. However, ORs always overestimate prevalence ratios when events have a common outcome. ${ }^{30}$ Adopting these models individually helped to have a holistic understanding of the factors associated with VI by looking at the log-likelihood ratio (Poisson), log odds (Logistic), and normalised coefficients (Probit) as suggested by Chen et al. ${ }^{30}$

The association of VI on our primary outcome (social isolation, depression and life satisfaction) was quantified. This approach was done by adopting Coarsened Exact Matching (CEM) by controlling for the factors significantly influencing VI. In this analysis, CEM allowed us to specify matching levels within the factors significantly influencing VI which ensures the degree of balance in the matching factors at the lowest level. Before matching, over $77 \%$ of imbalance existed among the covariates significantly influencing VI; however, after CEM matching, imbalances reduced to almost $0 \%$ (3.21E-15; see online supplementary table 2$)$.

Quantification of the association between VI and social isolation, depression and life satisfaction was performed by adopting three statistical models separately involving; modified negative binomial (NB), modified robust Poisson regression and modified generalised negative binomial (GNB) regression, respectively.

NB was applied due to the overdispersed nature of the raw social isolation scores where the variance exceeds the mean $\left(\sigma^{2}\right.$ vs $\mu=2.16$ vs 0.69$)$ and a significant $p$-value goodness of fit from Poisson estimation $(p<0.001)$. The NB provided an improved fit to the social isolation raw score and accounted better for overdispersion. Robust Poisson was applied to depression due to the dummy nature of the outcome variable. The choice of Poisson on depression was to estimate the prevalence ratio using the log ratio rather than log odds. The GNB was applied to life satisfaction raw scores due to the dispersion nature where the mean exceeds the variance $(\mu$ vs $\sigma^{2}=19.56$ vs 11.53 ). Robust SE was considered in the estimations and all analysis was carried out using Stata V.15 with $\mathrm{p}<0.05$ deemed significant.

\section{ETHICAL REQUIREMENTS}

SAGE Wave 2 study was approved by WHO's Ethical Review Board with reference number RPC149 and also, the Ethical and Protocol Review Committee, College of Health Sciences, University of Ghana, Accra, Ghana. Written informed consent was obtained from all study participants.

\section{PATIENTS AND PUBLIC INVOLVEMENT STATEMENT}

The questionnaire used for the SAGE Wave 2 was modified from that of SAGE Wave 1 due to patient experiences and priority lessons learnt. The design of SAGE Wave 2 was informed by the involvement of patients in Wave 1; modifications made were based on patient priorities. Recruitment of patients and conduct of the study were by the WHO SAGE Ghana Team. The WHO SAGE Ghana Team organises national stakeholders meeting to disseminate the findings of the national survey. A report of the national survey based on all data collected is provided to the general public and available on the WHO SAGE website.

\section{RESULTS}

The prevalence of VI was $17.1 \%$ (95\% CI 14.3 to 20.2) with high prevalence among women compared with men $(18.3 \%$ vs $15.7 \%)$ and increasing age depicting increasing prevalence of VI. Rao-Scott test of independence showed that except sex differential and marital status, there was a statistically significant association between all the other characteristics and status of VI $(\mathrm{p}<0.05$; see table 1$)$.

Inferential analysis involving Poisson, Logistic and Probit statistical models was carried out independently to assess covariates significantly influencing VI among older adults. The analysis showed in all the models that age groups, educational level, religion, region, SRH, place where a participant was born and difficulty in 
Table 1 Prevalence and demographic characteristics of visual impairment among older adults in Ghana, Study on Global Ageing and Adult Health Wave 2 from 2014 to 2015

\begin{tabular}{|c|c|c|c|c|}
\hline \multirow[b]{4}{*}{ Demographic variable } & \multirow[b]{3}{*}{ Total } & \multicolumn{2}{|c|}{ Visual impairment status } & \multirow[b]{4}{*}{ Rao-Scott $\chi^{2}$} \\
\hline & & No $(95 \% \mathrm{Cl})$ & Yes $(95 \% \mathrm{Cl})$ & \\
\hline & & 82.9 (79.8 to 85.6$)$ & 17.1 (14.3 to 20.2 ) & \\
\hline & $\mathbf{N}$ & (\%) & (\%) & \\
\hline Sex & & & & 2.88 \\
\hline Male & 1472 & 84.3 & 15.7 & \\
\hline Female & 2103 & 81.7 & 18.3 & \\
\hline Age group & & & & $29.72^{\star \star *}$ \\
\hline $50-59$ & 1295 & 88.8 & 11.2 & \\
\hline $60-69$ & 1105 & 83.6 & 16.4 & \\
\hline $70-79$ & 771 & 73.6 & 26.3 & \\
\hline $80+$ & 404 & 63.3 & 36.7 & \\
\hline Educational level & & & & $4.28^{* *}$ \\
\hline None & 1784 & 81.8 & 18.2 & \\
\hline Primary & 860 & 79.4 & 20.6 & \\
\hline SHS/MSLC & 811 & 88.7 & 11.3 & \\
\hline Tertiary & 120 & 81.3 & 18.7 & \\
\hline Marital status & & & & 2.27 \\
\hline Never married & 115 & 85 & 15 & \\
\hline Married & 2002 & 84.6 & 15.4 & \\
\hline Separated/divorced & 427 & 81.9 & 18.1 & \\
\hline Widowed & 1031 & 78.7 & 21.3 & \\
\hline Religion & & & & $9.74^{\star \star \star}$ \\
\hline None & 114 & 67.6 & 32.4 & \\
\hline Christian & 2563 & 81.5 & 18.5 & \\
\hline Islam & 665 & 90 & 10 & \\
\hline Primal indigenous & 222 & 88 & 12 & \\
\hline Place of residence & & & & $4.33^{\star}$ \\
\hline Urban & 1403 & 79.9 & 20.1 & \\
\hline Rural & 2172 & 85.7 & 14.3 & \\
\hline Currently working & & & & $25.42^{\star \star \star}$ \\
\hline No & 1282 & 74.3 & 25.7 & \\
\hline Yes & 2293 & 87 & 13 & \\
\hline Region & & & & $10.14^{\star \star \star}$ \\
\hline Ashanti & 586 & 82.6 & 17.4 & \\
\hline Brong Ahafo & 380 & 93.3 & 6.7 & \\
\hline Central & 461 & 91.5 & 8.5 & \\
\hline Eastern & 288 & 80.3 & 19.7 & \\
\hline Greater Accra & 339 & 62.7 & 37.3 & \\
\hline Northern & 360 & 92.3 & 7.7 & \\
\hline Upper East & 197 & 93 & 7 & \\
\hline Upper West & 185 & 90.1 & 9.9 & \\
\hline Volta & 330 & 79.5 & 20.5 & \\
\hline Western & 449 & 88 & 12 & \\
\hline $\mathrm{SRH}$ & & & & $30.64^{\star \star \star}$ \\
\hline
\end{tabular}


Table 1 Continued

\begin{tabular}{|c|c|c|c|c|}
\hline \multirow[b]{4}{*}{ Demographic variable } & \multirow[b]{3}{*}{ Total } & \multicolumn{2}{|c|}{ Visual impairment status } & \multirow[b]{4}{*}{ Rao-Scott $\chi^{2}$} \\
\hline & & No $(95 \% \mathrm{Cl})$ & Yes $(95 \% \mathrm{Cl})$ & \\
\hline & & 82.9 (79.8 to 85.6$)$ & 17.1 (14.3 to 20.2 ) & \\
\hline & $\mathbf{N}$ & (\%) & (\%) & \\
\hline Good & 2150 & 89 & 11 & \\
\hline Moderate & 1037 & 76.1 & 23.9 & \\
\hline Bad & 359 & 61 & 39 & \\
\hline Place of born & & & & $10.99^{* * *}$ \\
\hline Same locality & 2479 & 86.4 & 13.6 & \\
\hline Different locality & 1096 & 75.6 & 24.4 & \\
\hline Difficulty in work activity/HH & & & & $16.97^{\star \star \star}$ \\
\hline None & 1356 & 90 & 10 & \\
\hline Mild & 932 & 83.6 & 16.4 & \\
\hline Moderate & 960 & 76.8 & 23.2 & \\
\hline Severe/extreme & 203 & 60.5 & 39.5 & \\
\hline NCD status & & & & $22.66^{\star \star *}$ \\
\hline None & 2880 & 84.7 & 15.3 & \\
\hline $1+\mathrm{NCD}$ & 695 & 75.6 & 24.4 & \\
\hline WHR & & & & $3.81^{*}$ \\
\hline Low & 759 & 86.8 & 13.2 & \\
\hline Moderate & 1052 & 83 & 17 & \\
\hline High & 1545 & 79.8 & 20.2 & \\
\hline Hypertension status & & & & $14.01^{* * *}$ \\
\hline Normal & 1102 & 88.9 & 11.1 & \\
\hline Elevated & 749 & 84.3 & 15.7 & \\
\hline Hypertensive & 1724 & 78.7 & 21.3 & \\
\hline
\end{tabular}

Non-communicable disease (NCD) status comprises self-reporting of angina, arthritis, asthma, cataract, depression, diabetes, hypertension, chronic lung disease and stroke. $\mathrm{HH}$ is household work. NCDs score $(0=$ None, $1+=1+\mathrm{NCD})$.

${ }^{*} \mathrm{p}<0.05,{ }^{\star *} \mathrm{p}<0.01,{ }^{* \star *} \mathrm{p}<0.001$.

MSLC, Middle School Leaving Certificate; SHS, Senior High School; SRH, self-rated health; WHP, waist-hip ratio.

work activity were significantly associated with VI (see table 2).

\section{Association of visual impairment with social isolation,} depression and life satisfaction

In order to quantify the association between VI and social isolation, depression and life satisfaction, a significant mean difference of raw score was estimated and analysis showed that those without VI were at an advantage compared with VI older adults. Moreover, further analysis showed that there was a significant relationship between VI and our primary outcomes (social isolation, depression and life satisfaction). Moreover, wherever depression occurs, social isolation increased and lower life satisfaction experienced (see online supplementary tables 3 and 4).

Inferential analysis involving NB, Poisson and GNB modified with CEM was carried out in quantifying the association between VI and social isolation, depression and life satisfaction, respectively, controlling for significant factors influencing VI among older adults.

For social isolation, the log-likelihood score among older adults with VI was 0.25 more compared with those without VI and was statistically significant $(\beta$ $(95 \% \mathrm{CI})=0.25$ (0.03 to 0.47$), \mathrm{p}<0.01)$ as predicted by NB (see table 3).

The association of VI with depression also showed that the prevalence of depression among older adults with VI was significantly $90 \%$ higher compared with those without VI (aPR (95\% CI)=1.90 (1.17 to 3.09), $\mathrm{p}<0.001)$ as predicted by modified Poisson regression (see table 3 ).

Furthermore, life satisfaction correlates analysis depicted that the predicted probability of life satisfaction score was significantly 0.04 less among older adults with VI compared with those without VI $(\beta(95 \% \mathrm{CI})=-0.04$ $(-0.08$ to -0.01$), \mathrm{p}<0.01$; see table 3$)$. 
Table 2 Inferential analysis showing factors associated with visual impairment among older adults in Ghana, Study on Global Ageing and Adult Health Wave 2 from 2014 to 2015

\begin{tabular}{|c|c|c|c|}
\hline & Poisson & Logistic & Probit \\
\hline Covariate & aPR $(95 \% \mathrm{Cl})$ & aOR $(95 \% \mathrm{Cl})$ & aß $(95 \% \mathrm{Cl})$ \\
\hline \multicolumn{4}{|l|}{ Sex } \\
\hline Male & Ref & Ref & Ref \\
\hline Female & 0.96 (0.75 to 1.24$)$ & 0.93 (0.64 to 1.36$)$ & $-0.04(-0.24$ to 0.17$)$ \\
\hline \multicolumn{4}{|l|}{ Age group } \\
\hline $50-59$ & Ref & Ref & Ref \\
\hline $60-69$ & $1.39(1.07 \text { to } 1.789)^{*}$ & $1.53(1.07 \text { to } 2.17)^{\star}$ & $0.23(0.04 \text { to } 0.42)^{\star}$ \\
\hline $70-79$ & $1.81(1.35 \text { to } 2.24)^{\star * *}$ & $2.26(1.51 \text { to } 3.39)^{\star \star \star}$ & $0.46(0.25 \text { to } 0.67)^{\star \star \star}$ \\
\hline $80+$ & $2.35(1.74 \text { to } 3.17)^{\star \star \star}$ & $3.52(2.28 \text { to } 5.43)^{\star \star \star}$ & $0.71(0.47 \text { to } 0.95)^{\star \star \star}$ \\
\hline \multicolumn{4}{|l|}{ Educational level } \\
\hline SHS/MSLC & Ref & Ref & Ref \\
\hline None & $1.83(1.25 \text { to } 2.67)^{\star \star}$ & $2.37(1.38 \text { to } 4.06)^{\star *}$ & $0.45(0.17 \text { to } 0.74)^{* *}$ \\
\hline Primary & $1.87(1.31 \text { to } 2.67)^{\star \star \star}$ & $2.39(1.46 \text { to } 3.93)^{\star \star \star}$ & $0.46(0.21 \text { to } 0.72)^{\star \star \star}$ \\
\hline Tertiary & 1.38 (0.80 to 2.38$)$ & 1.58 (0.78 to 3.53$)$ & $0.25(-0.19$ to 0.69$)$ \\
\hline \multicolumn{4}{|l|}{ Marital status } \\
\hline Married & Ref & Ref & Ref \\
\hline Never married & 1.07 (0.67 to 1.70$)$ & 1.07 (0.57 to 2.04$)$ & $0.08(-0.26$ to 0.42$)$ \\
\hline Separated/divorced & 1.01 (0.72 to 1.42$)$ & 1.02 (0.63 to 1.65$)$ & $0.02(-0.23$ to 0.28$)$ \\
\hline Widowed & 0.78 (0.60 to 1.02$)$ & 0.74 (0.51 to 1.07$)$ & $-0.15(-0.35$ to 0.05$)$ \\
\hline \multicolumn{4}{|l|}{ Religion } \\
\hline Islam & Ref & Ref & Ref \\
\hline None & $2.27(1.50 \text { to } 3.44)^{\star \star \star}$ & $3.76(2.03 \text { to } 6.96)^{\star \star \star}$ & $0.71(0.37 \text { to } 1.04)^{\star * \star}$ \\
\hline Christian & $1.73(1.18 \text { to } 2.53)^{\star \star}$ & $2.11(1.25 \text { to } 3.56)^{\star \star}$ & $0.37(0.11 \text { to } 0.64)^{\star \star}$ \\
\hline Primal Indigenous & 1.65 (0.97 to 2.81$)$ & 1.88 (0.93 to 3.79$)$ & $0.28(-0.09$ to 0.66$)$ \\
\hline \multicolumn{4}{|l|}{ Place of residence } \\
\hline Rural & Ref & Ref & Ref \\
\hline Urban & 1.14 (0.86 to 1.51$)$ & 1.19 (0.79 to 1.78$)$ & $0.08(-0.13$ to 0.30$)$ \\
\hline \multicolumn{4}{|l|}{ Currently working } \\
\hline No & Ref & Ref & Ref \\
\hline Yes & 0.88 (0.67 to 1.14$)$ & 0.83 (0.57 to 1.21$)$ & $-0.11(-0.31$ to 0.10$)$ \\
\hline \multicolumn{4}{|l|}{ Region } \\
\hline Upper West & Ref & Ref & Ref \\
\hline Ashanti & 1.56 (0.84 to 2.88$)$ & 1.77 (0.79 to 3.96$)$ & $0.26(-0.14$ to 0.68$)$ \\
\hline Brong Ahafo & 0.63 (0.35 to 1.17$)$ & 0.57 (0.27 to 1.22$)$ & $-0.36(-0.73$ to 0.02$)$ \\
\hline Central & 0.85 (0.46 to 1.58$)$ & 0.82 (0.37 to 1.79$)$ & $-0.13(-0.53$ to 0.26$)$ \\
\hline Eastern & 1.62 (0.86 to 3.04$)$ & 1.81 (0.78 to 4.19$)$ & $0.28(-0.16$ to 0.73$)$ \\
\hline Greater Accra & $2.93(1.53 \text { to } 5.59)^{\star * *}$ & $4.92(1.94 \text { to } 12.47)^{\star \star \star}$ & $0.85(0.35 \text { to } 1.35)^{\star \star *}$ \\
\hline Northern & 0.90 (0.45 to 1.77$)$ & $0.90(0.38$ to 2.09$)$ & $-0.07(-0.50$ to 0.35$)$ \\
\hline Upper East & 0.70 (0.33 to 1.48$)$ & 0.67 (0.27 to 1.66$)$ & $-0.24(-0.70$ to 0.22$)$ \\
\hline Volta & $1.83(1.04 \text { to } 3.22)^{*}$ & $2.19(1.04 \text { to } 4.58)^{*}$ & $0.39(0.01 \text { to } 0.77)^{\star}$ \\
\hline Western & 1.19 (0066 to 2.14$)$ & 1.24 (0.58 to 2.65$)$ & $0.06(-0.32$ to 0.44$)$ \\
\hline \multicolumn{4}{|l|}{$\mathrm{SRH}$} \\
\hline Good & Ref & Ref & Ref \\
\hline Moderate & $1.54(1.11 \text { to } 2.14)^{\star \star}$ & $1.81(1.18 \text { to } 2.75)^{\star \star}$ & $0.33(0.11 \text { to } 0.56)^{\star \star}$ \\
\hline
\end{tabular}


Table 2 Continued

\begin{tabular}{|c|c|c|c|}
\hline & Poisson & Logistic & Probit \\
\hline Covariate & aPR $(95 \% \mathrm{Cl})$ & aOR $(95 \% \mathrm{Cl})$ & aß $(95 \% \mathrm{Cl})$ \\
\hline Bad & $1.95(1.22 \text { to } 3.10)^{\star \star}$ & $2.74(1.41 \text { to } 5.34)^{\star *}$ & $0.58(0.21 \text { to } 0.95)^{\star \star}$ \\
\hline \multicolumn{4}{|l|}{ Place of born } \\
\hline Same locality & Ref & Ref & Ref \\
\hline Different locality & $1.38(1.10 \text { to } 1.73)^{\star *}$ & $1.65(1.17 \text { to } 2.30)^{\star *}$ & $0.28(0.10 \text { to } 0.46)^{\star *}$ \\
\hline \multicolumn{4}{|c|}{ Difficulty in work activity/HH } \\
\hline None & Ref & Ref & Ref \\
\hline Mild & $1.56(1.15 \text { to } 2.09)^{\star \star}$ & $1.81(1.22 \text { to } 2.68)^{\star \star}$ & $0.31(0.10 \text { to } 0.52)^{\star \star}$ \\
\hline Moderate & 1.41 (0.86 to 2.29$)$ & $1.48(0.76$ to 2.91$)$ & $0.20(-0.17$ to 0.56$)$ \\
\hline Severe & 1.54 (0.95 to 2.49$)$ & 1.91 (0.90 to 4.07$)$ & $0.35(-0.05$ to 0.76$)$ \\
\hline \multicolumn{4}{|l|}{ Extreme } \\
\hline \multicolumn{4}{|l|}{ NCD status } \\
\hline None & Ref & Ref & Ref \\
\hline $1+N C D$ & 0.94 (0.79 to 1.11$)$ & 0.94 (0.71 to 1.23$)$ & $-0.03(-0.18$ to 0.13$)$ \\
\hline \multicolumn{4}{|l|}{ WHR } \\
\hline Low & Ref & Ref & Ref \\
\hline Moderate & 1.08 (0.79 to 1.48$)$ & $1.13(0.74$ to 1.74$)$ & $0.06(-0.17$ to 0.29$)$ \\
\hline High & 1.04 (0.79 to 1.37$)$ & 1.08 (0.73 to 1.60$)$ & $0.04(-0.18$ to 0.26$)$ \\
\hline \multicolumn{4}{|l|}{ Hypertension status } \\
\hline Normal & Ref & Ref & Ref \\
\hline Elevated & 1.04 (0.81 to 1.32$)$ & 1.05 (0.74 to 1.48$)$ & $0.02(-0.17$ to 0.21$)$ \\
\hline Hypertension & 1.17 (0.96 to 1.44$)$ & 1.23 (0.91 to 1.65$)$ & $0.11(-0.05$ to 0.27$)$ \\
\hline
\end{tabular}

Non-communicable disease (NCD) status comprises self-reporting of angina, arthritis, asthma, cataract, depression, diabetes, hypertension, chronic lung disease, and stroke. $\mathrm{HH}$ is household work. NCDs score $(0=$ None, $1+=1+\mathrm{NCD})$.

${ }^{*} \mathrm{p}<0.05,{ }^{* *} \mathrm{p}<0.01,{ }^{* \star *} \mathrm{p}<0.001$.

aOR, adjusted OR; aPR, adjusted prevalence ratio; MSLC, Middle School Leaving Certificate; SHS, Senior High School; SRH, self-rated health; WHR, waist-hip ratio.

\section{DISCUSSION}

Visual impairment is a social and public health issue especially in developing countries ${ }^{17}$ which increases with age, due to various life-course changes. ${ }^{31}$ This analysis identified the prevalence of VI among older adults to be $17.1 \%$. This prevalence is similar to the findings of Saw et al who identified a prevalence of $17.3 \%$ VI among older adults in Singapore, ${ }^{32}$ but lower to the findings of Hong et al in Korea $(22.5 \%) .{ }^{10}$ Some studies in Ghana corroborate our findings with a comparable prevalence of $17.1 \% .^{33}$ However, other studies found higher prevalence $(21.7 \%$ and $18.4 \%)^{3435}$ while another had a relatively very low prevalence of $3.87 \%$ (combined bilateral and unilateral VI). ${ }^{36}$ These differences are potentially due to the different population characteristics and different methodological assessment.

Factors associated with visual impairment among older adults aged $\mathbf{5 0}$ years and above in Ghana

This study identified a monotonic increasing age depicting an increasing prevalence of VI where age is significantly associated with VI among older adults. This is in conformity with another study. ${ }^{4}$ Educational level was identified to be associated and significantly influence VI among the participants, where older adults with tertiary education experience a high prevalence of VI. This high prevalence is not surprising and potentially due to many hours of academic work and having to read lots of materials with attendant strain on the eyes as hypothesised that prolong reading has a significant impact on visual function loss among students. ${ }^{37}$ Disparities in VI were identified among the different religious groups. Older adults with no religion and Christians experienced more VI prevalence, highlighting the need for assessment of sociocultural factors in the optimal care of older adults with VI.

The geographical location (region) in this study significantly influenced VI, where older adults in Greater Accra (the most urbanised region in Ghana) were more likely to experience VI compared with older adults in the Upper West region (more rural). This could be relatively due to higher levels of education and potential occupational exposures. The urban older adults might probably have engaged in occupations requiring more reading and strain on the eyes relative to more manual and mechanical 
Table 3 Inferential analysis showing the association between visual impairment and social isolation, depression and life satisfaction individually among older adults

\begin{tabular}{|c|c|c|c|}
\hline \multirow[b]{3}{*}{ Covariate } & Social isolation & Depression & Life satisfaction \\
\hline & NB with CEM & Poisson with CEM & GNB \\
\hline & $\beta(95 \% \mathrm{Cl})$ & aPR $(95 \% \mathrm{Cl})$ & $\beta(95 \% \mathrm{Cl})$ \\
\hline \multicolumn{4}{|l|}{ Visual impairment } \\
\hline No & Ref & Ref & Ref \\
\hline Yes & $0.25(0.03 \text { to } 0.47)^{\star \star}$ & $1.90(1.17 \text { to } 3.09)^{\star \star \star}$ & $-0.04(-0.08 \text { to }-0.01)^{\star \star}$ \\
\hline \multicolumn{4}{|l|}{ Sex } \\
\hline Male & Ref & Ref & Ref \\
\hline Female & $0.06(-0.31$ to 0.44$)$ & 1.97 (0.81 to 4.79 ) & $0.02(-0.03$ to 0.08$)$ \\
\hline \multicolumn{4}{|l|}{ Marital status } \\
\hline Married & Ref & Ref & Ref \\
\hline Never married & $0.06(-0.60$ to 0.76$)$ & $0.17(0.05 \text { to } 0.55)^{\star \star}$ & $0.14(0.05 \text { to } 0.22)^{\star \star}$ \\
\hline Separated/divorced & $0.69(0.27 \text { to } 1.12)^{\star \star \star}$ & 2.14 (0.84 to 5.47$)$ & $-0.07(-0.13 \text { to }-0.01)^{*}$ \\
\hline Widowed & $0.57(0.25 \text { to } 0.89)^{\star \star \star}$ & 1.83 (0.83 to 4.02 ) & $-0.07(-0.12 \text { to }-0.01)^{\star}$ \\
\hline \multicolumn{4}{|l|}{ Place of residence } \\
\hline Rural & Ref & Ref & Ref \\
\hline Urban & $-0.44(-0.70 \text { to }-0.18)^{\star \star \star}$ & 0.91 (0.50 to 1.67$)$ & $0.09(0.03 \text { to } 0.14)^{\star \star \star}$ \\
\hline \multicolumn{4}{|l|}{ Currently working } \\
\hline No & Ref & Ref & Ref \\
\hline Yes & $-0.35(-0.63 \text { to }-0.09)^{\star \star}$ & 0.86 (0.39 to 1.85$)$ & $0.07(0.03 \text { to } 0.12)^{\star \star}$ \\
\hline \multicolumn{4}{|l|}{ NCD status } \\
\hline None & Ref & Ref & Ref \\
\hline $1+\mathrm{NCD}$ & $-0.03(-0.34$ to 0.28$)$ & 1.21 (0.59 to 2.48 ) & $-0.04(-0.10$ to 0.02$)$ \\
\hline \multicolumn{4}{|l|}{ WHR } \\
\hline Low & Ref & Ref & Ref \\
\hline Moderate & $0.36(-0.04$ to 0.76$)$ & 0.83 (0.36 to 1.93 ) & $-0.05(-0.09$ to -0.002$)$ \\
\hline High & $0.45(0.02 \text { to } 0.88)^{*}$ & $0.72(0.32$ to 1.61$)$ & $-0.12(-0.18 \text { to }-0.06)^{\star \star \star}$ \\
\hline \multicolumn{4}{|l|}{ Hypertension status } \\
\hline Normal & Ref & Ref & Ref \\
\hline Elevated & $-0.01(-0.41$ to 0.38$)$ & 1.45 (0.61 to 3.41$)$ & 0.003 (-0.05 to 0.06$)$ \\
\hline Hypertension & $-0.05(-0.57$ to 0.22$)$ & 1.01 (0.54 to 1.87$)$ & $-0.03(-0.08$ to 0.02$)$ \\
\hline
\end{tabular}

Non-communicable disease (NCD) status comprises self-reporting of angina, arthritis, asthma, cataract, depression, diabetes, hypertension, chronic lung disease and stroke. NCDs score $(0=$ None, $1+=1+N C D)$.

${ }^{*} \mathrm{p}<0.05,{ }^{* *} \mathrm{p}<0.01,{ }^{* * *} \mathrm{p}<0.001$.

aPR, adjusted prevalence ratio; CEM, Coarsened Exact Matching; GNB, generalised negative binomial; NB, negative binomial; WHR, waisthip ratio.

occupations in the more rural sites according to Ghana 2010 population and housing census. ${ }^{38}$ The distribution of eye healthcare workers in Ghana is uneven, with the distribution being greater in the south (Accra) which has been documented by Potter et al. ${ }^{39}$ Our analysis, however, did not indicate that access to health facilities and practitioners translated into the lower prevalence of VI. Health utilisation and access analysis may be useful.

Experiencing any form of NCD, bad SRH, difficulty in work activity, high WHR and hypertension status resulted in the high prevalence and significant association with VI among older adults in Ghana. Comorbid conditions like diabetes, arterial hypertension, arthritis and others have emerged as significant threats to an individual's vision which have become more prevalent with increasing age. ${ }^{29}$ All these factors are associated with VI due to the epidemiological transition of human lifestyle behaviours (smoking, drinking, less exercise, bad eating behaviour and fewer fruits intake) which causes NCDs to influence VI.

\section{ASSOCIATION OF VISUAL IMPAIRMENT WITH SOCIAL ISOLATION, DEPRESSION AND LIFE SATISFACTION}

This analysis has established that there is a tremendous association between VI and social isolation, depression and life satisfaction among older adults. Vision is a key sensory modality for interpersonal interactions and social 
communication where people with vision loss have fewer opportunities to learn and modify social skills. ${ }^{40}$ This study has confirmed the association of VI with mental health both cross-sectional and longitudinal as suggested by Zheng et al. ${ }^{13}$

Social isolation has been identified as a risk factor for many negative health outcomes especially among older adults with VI. ${ }^{41}$ The association of VI with social isolation among older adults with VI could be a result of poor vision as they used to see during their youthful age which limits them in performing their daily tasks and impose emotional and psychological strain. This analysis is in congruence with a previous observation that visual acuity influences social isolation among older adults. ${ }^{41}$ In addition, social isolation affects effective treatment and is known to result in reduced attendance for healthcare services. ${ }^{42}$ Social isolation among VI could also be explained as a consequence of anxiety. Agoraphobia and social phobia have been found to be the most prevalent anxiety disorder in VI older adults. ${ }^{43}$ These conditions adversely affect the individual's ability to engage in meaningful social engagements and may be explored in future studies.

In addition, this study found an association between VI and depression, and that VI significantly influenced depression among older adults in Ghana, which is in line with previous study findings. ${ }^{34}{ }^{35}$ The relationship between depression is well established using both crosssectional and longitudinal approaches. VI has been found to be a consistent predictor of both onset and persistence of depression among older adults. ${ }^{44}$ This is consistent with the findings of this study. Similarly, a study on the association of comorbid anxiety and depression among older adults found an increased occurrence of various physical disorders including VI. ${ }^{45}$ The ageing process and its accompanying unavoidable physiological process may lead to a reduction in life satisfaction which ultimately causes depression. Older adults with VI may be worried by their condition with the inconveniences they have to live with, which makes them feel sad, lose interest in most things they usually enjoyed such as personal relationships and work or hobbies/recreation, predisposing them to depression. Life space and limited activities due to fear of falling have been reported to be a mediator of the relationship between eye disease and depression. ${ }^{46} 47$ Three distinct methods of adaptation for VI has been established. These include: acceptance of vision loss, negative impact on relationships and attitudes towards compensation. However, acceptance of vision loss and attitudes towards compensation was positively associated with depressive affect. ${ }^{48}$

In order to address and manage VI, life satisfaction is a key indicator to consider. Our study identified a negative significant relationship between VI and life satisfaction with VI older adults, having a significant decreasing probability count for life satisfaction. The diminishing life satisfaction may be as a result of dissatisfaction in: health situation, ability to perform daily living activities, personal needs and relationships, and conditions of living place.

The diminishing life satisfaction may be as a result of the perceived cost in procuring commodities for the treatment of VI, such as corrective lenses or for surgery. This is congruent with a study that found VI associated with a reduction in diverse areas of quality of life in older adults. ${ }^{49}$ Additionally, among VI older adults, lower life satisfaction has been identified to be more prevalent among those depressed as compared with those who were not depressed.$^{50}$ This is in line with the findings of this study. The severity of VI also determines the extent to which life satisfaction is affected. An older adult with VI reports increases in life dissatisfaction with increased severity of VI. ${ }^{51}$ Overall, this analysis shows that perceived health, ability to perform daily living activities, personal relationships, condition of living and overall satisfaction of life as a whole (life satisfaction key indicators) were negatively affected in older adults with VI in Ghana.

\section{LIMITATION}

Due to the design nature of WHO SAGE Wave 2, this study did not allow for assigning causational effects. Recall bias is a potential limitation that this study anticipates due to the longevity of experiences of the older adults in the past 12 months especially, on depression. However, the WHO SAGE used different methods of data collection to limit recall bias. Moreover, although this study adopted a more robust analysis matching technique to establish our findings, there are more issues to consider like other biological factors that could influence VI for holistic matching.

\section{CONCLUSION}

The prevalence of visual impairment is high and that, the prevalence is associated with increasing age, educational level and SRH. Visual impairment was identified to be associated with social isolation, depression and diminishing life satisfaction. In order to achieve sustainable development goal \#3 (Ensure healthy lives and promote wellbeing for all at all ages), a national focus on geriatric care as part of the implementation of the National Ageing Policy will garner improvement in the quality of life of the older adults with visual VI in Ghana. Eye health practitioners at all levels of the health systems should consider the psychosocial consequences of VI for the optimum care of the older adult client.

\section{Author affiliations}

${ }^{1}$ Community Health, University of Ghana Medical School, College of Health Sciences, University of Ghana, Accra, Ghana

${ }^{2}$ Ophthalmology Unit, Korle Bu Teaching Hospital, Accra, Greater Accra, Ghana ${ }^{3}$ Psychiatry Unit, Korle Bu Teaching Hospital, Accra, Greater Accra, Ghana ${ }^{4}$ National Cardiothoracic Centre, Korle Bu Teaching Hospital, Accra, Greater Accra, Ghana

${ }^{5}$ Anesthesia Department, Korle Bu Teaching Hospital, Accra, Greater Accra, Ghana ${ }^{6}$ Medicine and Therapeutics, School of Medicine, University of Ghana College of Health Sciences, Accra, Greater Accra, Ghana 
Acknowledgements The authors are grateful to all respondents and interviewers who made the SAGE survey in Ghana possible. Financial support was provided by the US National Institute on Aging through Interagency Agreements (OGHA 04034785; YA1323-08-CN-0020; Y1-AG-1005-01) with the World Health Organization and a Research Project Grant (R01 AG034479- 64401A1). WHO contributed financial and human resources to SAGE. The Ministry of Health, Ghana is supportive of SAGE. The University of Ghana's Department of Community Health contributed training facilities, data entry support, and storage of materials. The Ghana Statistical Office provided the sampling information for the sampling frame and updates.

Contributors JT, GF and AEY developed the concept. JT analysed the data. GF, $A E Y, A O Y$ and $G E-F$ contributed to writing the first draft manuscript. VB, AE, KE-M, $\mathrm{GM}$ and $\mathrm{RB}$ contributed to the writing and reviewing of the various sections of the manuscript. All the authors reviewed the final version of the manuscript before submission. All authors read and approved the final manuscript.

Funding Funding was obtained for the WHO SAGE Wave 2 Survey in Ghana. The data is made available for public use upon request. This analysis, however, did not have any funding support.

Competing interests None declared.

Patient consent for publication Not required.

Provenance and peer review Not commissioned; externally peer reviewed.

Data availability statement Data are available upon request.

Open access This is an open access article distributed in accordance with the Creative Commons Attribution Non Commercial (CC BY-NC 4.0) license, which permits others to distribute, remix, adapt, build upon this work non-commercially, and license their derivative works on different terms, provided the original work is properly cited, appropriate credit is given, any changes made indicated, and the use is non-commercial. See: http://creativecommons.org/licenses/by-nc/4.0/.

ORCID iD

John Tetteh http://orcid.org/0000-0002-1986-4103

\section{REFERENCES}

1 WHO. Blindness and vision impairment, 2019. Available: https:// www.who.int/news-room/fact-sheets/detail/blindness-and-visualimpairment [Accessed 18 April 2020].

2 Budenz DL, Bandi JR, Barton K, et al. Blindness and visual impairment in an urban West African population: the Tema eye survey. Ophthalmology 2012;119:1744-53.

3 World report on aging and health2015Geneva, SwitzerlandWorld Health Organizationhttps://apps.who.int/iris/bitstream/handle/10665/ 186463/9789240694811_eng.pdf;jsessionid=164E22BC6A4E23F9 D12A5DCE14FB672A?sequence $=1$

4 Carter TL. Age-Related vision changes: a primary care guide. Geriatrics 1994;49:46-7.

5 Abokyi S, llechie A, Nsiah P, et al. Visual impairment attributable to uncorrected refractive error and other causes in the Ghanaian youth: the University of Cape coast survey. J Optom 2016;9:64-70.

6 Akpabla JA. Causes of visual impairment in the Bolgatanga Municipality in the upper East region of Ghana. JOJ Ophthalmol;7.

7 Nuertey BD, Amissah-Arthur KN, Addai J, et al. Prevalence, causes, and factors associated with visual impairment and blindness among registered pensioners in Ghana. J Ophthalmol 2019;2019:1-10.

8 Mousa A, Courtright P, Kazanjian A, et al. Prevalence of visual impairment and blindness in upper Egypt: a gender-based perspective. Ophthalmic Epidemiol 2014;21:190-6.

9 Rius Ulldemolins A, Benach J, Guisasola L, et al. Why are there gender inequalities in visual impairment? Eur J Public Health 2019;29:661-6.

10 Hong YA, Kim SY, Kim S-H, et al. The association of visual impairment with clinical outcomes in hemodialysis patients. Medicine 2016;95:e3591.

11 Lartey SY, Aikins AK. Visual impairment amongst adult diabetics attending a tertiary outpatient clinic. Ghana Med J 2018;52:84-7.

12 Carabellese C, Appollonio I, Rozzini R, et al. Sensory impairment and quality of life in a community elderly population. J Am Geriatr Soc 1993;41:401-7.

13 Zheng DD, Swenor BK, Christ SL, et al. Longitudinal associations between visual impairment and cognitive functioning: the Salisbury eye evaluation study. JAMA Ophthalmol 2018;136:989-95.

14 Court H, McLean G, Guthrie B, et al. Visual impairment is associated with physical and mental comorbidities in older adults: a crosssectional study. BMC Med 2014;12:181.
15 Owsley C, McGwin G, Scilley K, et al. Effect of refractive error correction on health-related quality of life and depression in older nursing home residents. Arch Ophthalmol 2007;125:1471-7.

16 Ofeibea Amedo A, Adade S, Yaa Koomson N, et al. Influence of visual impairment on the quality of life: a survey of patients reporting at the low vision centre of the eastern regional hospital of Ghana. JOS 2016:1:1-13.

17 Guo C, Wang Z, He P, et al. Prevalence, causes and social factors of visual impairment among Chinese adults: based on a national survey. Int J Environ Res Public Health 2017;14:1-3.

18 Biritwum R, George M, Yawson A, et al. Ghana-Study on global ageing and adult Health-2007/8, wave 1. Geneva, Switzerland: World Health Organization, 2013. https://apps.who.int/healthinfo/systems/ surveydata/index.php/catalog/6/download/1940

19 Charlton K, Ware LJ, Menyanu E, et al. Leveraging ongoing research to evaluate the health impacts of South Africa's salt reduction strategy: a prospective nested cohort within the WHO-SAGE multicountry, longitudinal study. BMJ Open 2016;6:e013316.

20 Kowal P, Chatterji S, Naidoo N, et al. Data resource profile: the world Health organization study on global ageing and adult health (SAGE). Int J Epidemiol 2012;41:1639-49.

21 WHO. Waist circumference and waist-hip ratio. WHO, 2011 Available: https://apps.who.int/iris/bitstream/handle/10665/44583/ 9789241501491 eng.pdf?ua=1 [Accessed 29 October 2019].

22 American Heart Association. The facts about high blood pressure, 2017. Available: https://www.heart.org/en/health-topics/high-bloodpressure/the-facts-about-high-blood-pressure [Accessed 30 Oct 2019].

23 Virgili G, Acosta R, Grover LL, et al. Reading AIDS for adults with low vision. Cochrane Database Syst Rev 2013:CD003303.

24 WHO. Mental and behavioural disorders, 2019. Available: https://icd. who.int/browse10/2019/en\#/F32 [Accessed 22 April 2020].

25 Arokiasamy P, Uttamacharya U, Jain K, et al. The impact of multimorbidity on adult physical and mental health in low- and middle-income countries: what does the study on global ageing and adult health (SAGE) reveal? BMC Med 2015;13:178.

26 Fernández-Niño JA, Bonilla-Tinoco LJ, Manrique-Espinoza BS, et al. Work status, retirement, and depression in older adults: an analysis of six countries based on the study on global ageing and adult health (SAGE). SSM Popul Health 2018;6:1-8.

27 Jann B. ALPHAWGT: Stata module to compute Cronbach's alpha for weighted data. Boston College Department of Economics, 2004. https://ideas.repec.org/c/boc/bocode/s444101.html

28 WHO. International Statistical Classification of Diseases and Related Health Problems 10th Revision (ICD-10)-WHO Version for 2016 , 2016. Available: https://icd.who.int/browse10/2016/en\#/H49-H52 [Accessed 4 Nov 2019].

29 Resnikoff S, Kocur I. Non-Communicable eye diseases: facing the future. Community Eye Health 2014;27:41-3.

30 Chen W, Qian L, Shi J, et al. Comparing performance between log-binomial and robust poisson regression models for estimating risk ratios under model misspecification. BMC Med Res Methodol 2018;18:63

31 Coyle CE, Steinman BA, Chen J, et al. And self-reported vision status: their associations with social isolation in older adults. $J$ Aging Health 2017;29:128-48.

32 Saw S-M, Foster PJ, Gazzard G, et al. Undercorrected refractive error in Singaporean Chinese adults: the Tanjong Pagar survey. Ophthalmology 2004;111:2168-74.

33 Budenz DL, Bandi JR, Barton K, et al. Blindness and visual impairment in an urban West African population: the Tema eye survey. Ophthalmology 2012;119:1744-53.

34 Choi HG, Lee MJ, Lee S-M. Visual impairment and risk of depression: a longitudinal follow-up study using a national sample cohort. Sci Rep 2018;8:2083.

35 Evans JR, Fletcher AE, Wormald RPL. Depression and anxiety in visually impaired older people. Ophthalmology 2007;114:283-8.

36 Morny EKA, Boadi-Kusi SB, Ocansey S, et al. Assessing the Progress towards Achieving "VISION 2020: The Right to Sight" Initiative in Ghana. J Environ Public Health 2019;2019:1-10.

37 Kartha AG. The effect of prolonged reading on visual functions and reading performance in students with low vision. PHD. Queensland University of Technology, 2010. https://eprints.qut.edu.au/31847/

38 Ghana Statistical Service (GSS). 2010 population and housing census. Ghana: GSS, UN population, 2014. https://statsghana.gov. $\mathrm{gh} / \mathrm{gssmain} / \mathrm{fileUpload/pressrelease/Urbanisation \% 20in \% 20Ghana.}$ pdf

39 Potter A, Debrah O, Ashun J, et al. Eye health systems assessment (EHSA): Ghana country report. Ghana Health Serv Int Cent Eye Health Sightsavers 2013:1-9. 
40 Jindal-Snape D. Generalization and maintenance of social skills of children with visual impairments: Self-evaluation and the role of feedback. J Vis Impair Blind 2004;98:470-83.

41 Coyle CE, Steinman BA, Chen J, et al. And self-reported vision status: their associations with social isolation in older adults. J Aging Health 2017;29:128.

42 Thiagalingam S, Cumming RG, Mitchell P. Factors associated with undercorrected refractive errors in an older population: the blue Mountains eye study. Br J Ophthalmol 2002;86:1041-5.

43 van der Aa HPA, Comijs HC, Penninx BWJH, et al. Major depressive and anxiety disorders in visually impaired older adults. Invest Ophthalmol Vis Sci 2015;56:849-54.

44 Chou K-L. Combined effect of vision and hearing impairment on depression in older adults: evidence from the English longitudinal study of ageing. J Affect Disord 2008;106:191-6.

$45 \mathrm{Kang} \mathrm{H}-\mathrm{J}$, Bae K-Y, Kim S-W, et al. Impact of anxiety and depression on physical health condition and disability in an elderly Korean population. Psychiatry Investig 2017;14:240-8.

46 Zhang X, Bullard KM, Cotch MF, et al. Association between depression and functional vision loss in persons 20 years of age or older in the United States, NHANES 2005-2008. JAMA Ophthalmol 2013;131:573-81.

47 Popescu ML, Boisjoly $\mathrm{H}$, Schmaltz $\mathrm{H}$, et al. Explaining the relationship between three eye diseases and depressive symptoms in older adults. Invest Ophthalmol Vis Sci 2012;53:2308-13.

48 Tolman J, Hill RD, Kleinschmidt JJ, et al. Psychosocial adaptation to visual impairment and its relationship to depressive affect in older adults with age-related macular degeneration. Gerontologist 2005;45:747-53.

49 Bekibele CO, Gureje O. Impact of self-reported visual impairment on quality of life in the lbadan study of ageing. $\mathrm{Br} J$ Ophthalmol 2008;92:612-5.

50 Brunes A, Heir T. Major depression in individuals with visual impairment, associations with characteristics of vision loss, and relation to life satisfaction. SSRN scholarly paper ID 3323116. Rochester, NY: Social Science Research Network, 2019.

51 Crews JE, Chou C-F, Zhang X, et al. Health-Related quality of life among people aged $\geq 65$ years with self-reported visual impairment: findings from the 2006-2010 behavioral risk factor surveillance system. Ophthalmic Epidemiol 2014;21:287-96. 